\title{
Português como Língua de Acolhimento (PLAc): transformando Não-lugares em Lugares no contexto das migrações forçadas
}

\author{
Luiza Silva de Andrade ${ }^{1}$ \\ Departamento de Letras Modernas, Universidade de São Paulo, São Paulo, SP, Brasil
}

Resumo: Este artigo faz uma ligação entre a Linguística Aplicada e a Antropologia ao refletir sobre a experiência de assentamento no país de acolhimento como um trânsito do não-lugar ao lugar no contexto da Supermodernidade conforme elaborado pelo Antropólogo Marc Augé (1995). Partindo de uma reflexão teórico-conceitual, o artigo ilustra o conceito de não-lugar com uma experiência prática, argumentando que a migração causa o esvaziamento da individualidade do sujeito e a ansiedade da ausência de hipóteses de passado e futuro. Sem a conexão relacional e identitária com o país de assentamento - processo intensificado pela ausência da língua local - os migrantes continuam a vivenciar seu novo mundo como um não-lugar. Assim, partindo de uma revisão bibliográfica, o ensino de Português como Língua de Acolhimento (PLAC) no Brasil é entendido como uma ponte entre não-lugar e lugar, atuando como instrumento catalizador do processo de ressignificação do novo espaço habitado pelos migrantes.

Palavras-chave: PLAc; Língua de Acolhimento; Não-lugar.

Title: Portuguese as Language of Reception: transforming Non-places into Places in the context of forced migration

Abstract: This article connects Applied Linguistics to Anthropology by reflecting on the experience of settlement in the country of reception as a form of transit from places to non-places in the context of Supermodernity as proposed by the anthropologist Marc Augé (1992). Starting from a theoretical-conceptual reflection, this paper illustrates the concept of non-place with a practical example to argue that the migration transit empties the migrants of individuality and builds feelings of anxiety coming from the absence of hypothesis of past or future. Lacking ties with the place of settlement, and without a mastery of local language, migrants continue to experience their new settlement's scenario as a non-place. Thus, building on a literature review, the teaching of Portuguese as a Language of Reception in Brazil is presented as a bridge between non-place and place, acting as a catalyst in the process of (re)signifying the new space inhabited by migrants.

Keywords: PLAc; Language of Reception; Non-place.

\footnotetext{
${ }^{1}$ Mestre em Antropologia Social e Cultural pela Vrije Universiteit Amsterdam (VU), Especialista em Estudos Linguísticos e Bacharel em Comunicação Social pela Universidade Federal de Minas Gerais (UFMG). Sóciocolaboradora da Associação Mineira dos Professores de Português como Língua Estrangeira (AMPPLIE). ORCID: https://orcid.org/0000-0001-7062-0203. E-mail: silvadeandradeluiza@gmail.com.
} 


\section{Introdução}

Acompanhando a tendência de intensificação dos fluxos migratórios contemporâneos, o Ensino de Português como Língua de Acolhimento (PLAc) vem ganhando cada vez mais espaço no Brasil. São várias as iniciativas de instituições como universidades e escolas, bem como de caráter comunitário, como associações de bairro e grupos religiosos, que têm se organizado de forma a auxiliar os imigrantes em seus reassentamentos no país de acolhimento. Apesar do aumento no número de iniciativas de acolhimento, o campo de PLAc ainda carece não só de verbas e apoio do governo, mas também de investigações epistemológicas que favoreçam o desenvolvimento da modalidade que, longe de ser uma simples adaptação do ensino de Português como Língua Estrangeira (PLE), constitui-se como uma modalidade que tanto integra quanto se forma a partir de várias áreas epistemológicas, como a psicologia, a antropologia, e a Linguística Aplicada. Partindo deste campo multidisciplinar, este artigo faz uma ligação entre a Antropologia e a Linguística Aplicada ao contextualizar o campo de PLAc em um cenário de Supermodernidade, conforme proposto pelo Antropólogo Marc Augé (1992).

A primeira seção apresenta uma reflexão teórico-conceitual sobre o contexto de Supermodernidade, e os conceitos-chave lugar e não-lugar. A origem desta reflexão deu-se a partir da experiência de um trabalho de campo de cunho etnográfico-antropológico realizado em 2013 em Brasiléia, no estado do Acre. Durante esta pesquisa, o contato e a convivência com os migrantes no abrigo tornaram claros os conceitos de lugar e não-lugar enquanto vivenciados na prática. Em sequência, abordamos o cenário contemporâneo das migrações forçadas e como esse movimento é manifestado no Brasil, ilustrando-o com detalhes da experiência prática do trabalho de campo antropológico acima mencionada. Em seguida, traçamos algumas considerações sobre o PLAc no Brasil a partir de uma revisão bibliográfica de publicações acadêmicas sobre língua de acolhimento em todo o mundo. Finalmente, partindo de uma análise dos relatos de experiências práticas de iniciativas de ensino de PLAc recém-publicados por outros pesquisadores, o artigo propõe o ensino de PLAc como um processo catalizador de transformação de não-lugares em lugares para os imigrantes acolhidos no Brasil.

\section{O contexto Pós-moderno}

A pós-modernidade é um eterno ciclo de ressignificação. Quem somos? De onde viemos? Qual é a verdade e quem são os outros? Fluxos migratórios contínuos, deslocamentos em massa, excesso de informação, de produtos, de possibilidades; são estes os elementos, para o sociólogo Zygmunt Bauman, inerentes à pós-modernidade, ou Modernidade Líquida (2000). "Abandone toda a esperança de totalidade, futuro, bem como passado, você que adentra o mundo da modernidade líquida", diz o sociólogo em seu ensaio sobre a emancipação em Modernidade Líquida (2000, p.22). Para o autor, as certezas que permitiam a estabilidade do mundo social na modernidade são desconstruídas neste novo período em 
que vivemos. Isto significa dizer que o caráter estável do ser, que denota o papel social, status marital, ou função laboral, poderia ser substituído pelo estar, que denota transitoriedade.

É neste contexto de conflito entre modernidade e pós-modernidade que o antropólogo francês Marc Augé (1992) propõe a Supermoderndade não como uma oposição, mas um desdobramento da modernidade. Para Augé, o caráter estável da modernidade está fortemente ligado ao conceito de Lugar Antropológico, que atribui significado ao espaço a partir do momento em que é vivenciado, experienciado pelos sujeitos. Em seu ensaio sobre os não-lugares, o antropólogo propõe uma diferenciação entre os conceitos de lugar e espaço, em que o primeiro é dotado de significação por parte dos sujeitos, é construído e os constrói mutuamente. Já ao segundo é atribuído um significado espacial no sentido físico de um objeto que ocupa um espaço. O espaço, portanto, é uma categoria mais ampla de delimitação geográfica ou, ainda, abstrata. $\mathrm{O}$ espaço pode ser preenchido por objetos que contêm massa, ou por um vazio, na ausência de objetos. Já a definição de Lugar Antropológico, segundo Augé, vai além do espaço. É uma construção elaborada individualmente ou coletivamente, que atribui significado ou tem seu significado atribuído pelo uso e pela relação que se tem com este espaço. Ao espaço é atribuído uma história, uma relação, e uma formação identitária. Assim, ele pode ser identificado como um lugar. Em contraste, aos espaços de transição, de movimento, de passagem - muitos deles tidos como espaços coletivos e ao mesmo tempo de ninguém, típicos de representações da pós-modernidade - como aeroportos, estradas, rotas de migração, campos de refugiados, entre outro, é atribuído o caráter de não-lugar.

Se um lugar pode ser definido como identitário, relacional e histórico, um espaço que não pode ser definido como identitário, nem como relacional, nem como histórico, definirá um não-lugar. A hipótese defendida aqui é a de que a Supermodernidade é produtora de não-lugares, isto é, de espaços que não são, em si, lugares antropológicos [...] (AUGÉ, 2018, p. 61)

É preciso ter em mente, conforme reitera o autor, que os não-lugares não são denotações negativas entendidas como opostas aos lugares. A diferença entre os dois perpassa a ideia de que os lugares são espaços antropológicos, onde o sujeito existe e vivencia o mundo, é "o lugar do sentido inscrito e simbolizado, o lugar antropológico". (AUGÉ, 2018, p. 61)

\section{Supermodernidade e o contexto das migrações forçadas no Brasil}

Em Stuck in a non-place: Haitian migrants' temporary settlement in Brazil and perceptions of time, uma tese de mestrado de cunho antropológico realizada nos anos de 2012 e 2013, o estudo de um abrigo temporário de imigrantes no estado do Acre indica na prática a existência de um não-lugar. Durante o trabalho de campo, foi possível analisar a forma como os sujeitos lidam com este espaço temporário que acaba se tornando permanente (ANDRADE, 2013). No relato etnográfico, o abrigo de imigrantes montado na cidade de Brasiléia, na fronteira com a Bolívia, apresenta características típicas de um espaço de transição. No local, havia cerca de 200 leitos improvisados para mais de mil imigrantes que chegavam ao país em 
busca de novas oportunidades de vida. As refeições providenciadas pela Secretaria de Justiça e Direitos Humanos (SEJUDH-AC) eram contadas cabeça por cabeça, o que significa que os 200 a 400 novos migrantes que chegavam diariamente ao abrigo não podiam se alimentar. Por vezes, habitantes locais voluntários traziam refeições para os migrantes - em sua maioria haitianos - para Ihes aliviar parte do sofrimento do processo migratório. Muito levaram entre 10 e 20 dias em suas trajetórias no percurso entre Haiti e Brasil. Outros, sem dinheiro por terem sido roubados pelos Coiotes durante o trânsito migratório, acabavam passando alguns meses no Peru ou na Bolívia, fazendo bicos para juntar mais algum dinheiro com o objetivo de chegar ao Brasil.

No abrigo, os migrantes compartilhavam um sentimento de ansiedade e de vergonha. Apesar de estarem em contato com suas famílias no Haiti por meio de celulares com chip de internet 3G, raramente eles mencionavam as condições encontradas no abrigo para seus amigos e família. Lá, eles permaneciam por, pelo menos, entre duas e oito semanas iniciais, até a confecção de um Cadastro de Pessoa Física (CPF) brasileiro, proporcionado pelo visto humanitário. Então, com o CPF em mãos, porém sem dinheiro, os migrantes passavam ainda por uma segunda fase de assentamento temporário, em que muitos permaneciam no abrigo esperando até 4 meses por uma oportunidade de emprego ${ }^{2}$. Não diferentemente de outros fluxos migratórios intensos, como é o caso dos venezuelanos no estado de Roraima, muitos destes migrantes tinham vidas econômicas ativas, planos para o futuro, relacionamentos e bens materiais em seu país de origem. Antes de serem forçados a sair, tinham tetos sobre suas cabeças, e nunca antes haviam passado por situações de tamanho descaso e humilhação, conforme relatado pelos participantes durante o estudo de campo (ANDRADE, 2013).

Não raro os processos migratórios são acompanhados por sentimentos de ansiedade, humilhação e descaso. Para Augé (2018), O espaço do viajante constitui-se como o arquétipo do não-lugar. Segundo o autor, o movimento acrescenta à coexistência combinada dos lugares e não-lugares a "experiência particular de uma forma de solidão". Dessa maneira, continua o autor, não é de se espantar que seja entre

Os viajantes acidentais, de pretexto ou de ocasião, que estejamos aptos a encontrar a evocação profética do espaço, onde nem a identidade, nem a relação, nem a história fazem realmente sentido, onde a solidão é sentida como superação ou esvaziamento da individualidade, onde só o movimento das imagens deixa entrever, por instantes, àquele que as olha fugir, a hipótese de um passado e a possibilidade de um futuro. (AUGÉ, 2018, p. 67)

Neste trecho, o autor elabora o arquétipo de não-lugar a partir da experiência do viajante em movimento. Contudo, como será sentida essa experiência do esvaziamento da individualidade em lugares fixos, onde não há o movimento das imagens por entre as quais pode-se entrever a hipótese de um passado e a possibilidade de um futuro?

\footnotetext{
${ }^{2}$ A SEJUDH-AC organizou uma espécie de rede de colaboradores entre empresas interessadas em contratar novos trabalhadores, para que pudessem ir até o abrigo selecionar seus novos empregados. Em 2013, a maioria das empresas vinham da região Sul do país em ônibus fretados, e já voltavam aos seus estados após os processos seletivos com ônibus carregados com entre 15 e 40 migrantes por vez (ANDRADE, 2013).
} 
O caso do abrigo em Brasiléia apresenta justamente este fator complicador do movimento migratório: $O$ caráter temporário, porém permanente do abrigo. Apesar de se propor como um caráter temporário, a estadia no abrigo, como é o caso em diversos campos de assentamento de refugiados espalhados pelo mundo, é prolongada pelas condições estruturais do país de acolhimento. Dessa forma, as condições de higiene e assentamento que podem ser toleradas por serem temporárias no não-lugar, acabam tornando-se permanentes por meses a perder de vista. A dicotomia entre este espaço que é ambos lugar e não-lugar parece estar presente em grande parte dos fluxos migratórios contemporâneos. Quando o sujeito sai do seu lugar de origem, ainda dotado de agência, ele transita por uma infinidade de não-lugares, espaços com os quais ele não estabelece uma relação, os quais não lhe significam uma história, e que não fazem parte de suas identidades. Aqui, trazemos a concepção de Augé para uma esfera mais subjetiva inerente à pós-modernidade, em que não há realidades absolutas, apenas realidades subjetivas de vivência e experiência do mundo. Assim, espaços que são tipos como lugares para os habitantes locais, podem ser tidos como não-lugares para quem nele acaba de ser reassentado.

O contexto dos campos de refugiados parece se repetir em diversas partes do mundo. Tendo sido forçados a sair de seus contextos de origem, os habitantes destes campos passam por um processo de esvaziamento do ser, uma dessignificação de suas individualidades em prol da organização sistêmica dos espaços, de forma que passam a ser considerados apenas números - como no CPF Brasileiro (ANDRADE, 2013). Tal esvaziamento de sentido do ser é reforçado ainda mais pela perda das capacidades comunicacionais linguísticas, já que, estando em espaço culturalmente diferente do de origem, essas pessoas perdem também a capacidade de se expressar. Para Augé (2018, p.67), "Por trás da ronda das horas e dos pontos fortes da paisagem, encontramos, na verdade, palavras e linguagens [...] O lugar se completa pela fala, a troca alusiva de algumas senhas, na convivência e na intimidade cúmplice dos locutores." Dessa forma, para Augé, além do tempo e dos espaços, o que atribui o caráter de Lugar a um espaço, é a língua compartilhada.

Narrativas de migração como as encontradas em Staudt (2018), que trabalhou as elaborações orais de migrantes haitianos no Brasil, ou em Papadopoulus, Tsioli e Androulakis (2019), que desenvolveram um projeto interdisciplinar linguístico antropológico e psicológico com os refugiados que residiam em Atenas, Tessalônica e na ilha de Lesbos, indicam que grande parte desta ansiedade é construída a partir do esvaziamento das possibilidades de comunicação causados pela falta da língua local. Em contextos como esses, portanto, o estabelecimento de projetos de bem-estar linguístico vai além da capacitação para atividades econômicas locais. Nestes espaços, poder se comunicar é dotar-se novamente de agência, tornar-se novamente um ser, em vez de apenas um estar de caráter inerentemente temporário, como geralmente lhes é atribuído.

É importante ressaltar que o Brasil ocupa uma posição de destaque nos fluxos migratórios contemporâneos. Segundo o Alto Comissariado das Nações Unidas para Refugiados (ACNUR), das 79,5 milhões de pessoas forçadas a deixar seu país de origem, 26 milhões são considerados refugiados, e 45,7 milhões são pessoas deslocadas. Do total, 3,6 
milhões são venezuelanos deslocados de seu país. Além disso, $80 \%$ das pessoas deslocadas no mundo estão em países ou territórios afetados por grave insegurança alimentar ou desnutrição. Em 2018, o Brasil havia reconhecido cerca de 11 mil refugiados no país. 36\% destes eram sírios e $15 \%$ congoleses. Contudo, estes 11 mil surgiram a partir de mais de 80 mil pedidos de refúgio, sendo cerca de 60 mil deles venezuelanos. Há, ainda, solicitações de haitianos, cubanos, chineses, bengaleses, entre outros. Em janeiro de 2020, o Brasil havia reconhecido o refúgio de 37 mil venezuelanos, tornando-se o país com o maior número de refugiados do país vizinho da américa Latina (ACNUR, 2020). Até 2016, haviam sido emitidos 67 mil autorizações de residência a haitianos - cujos pedidos de refúgio frequentemente são negados por serem considerados migrações econômicas pelo o governo Brasileiro (IPPDH, 2017), uma vez que

é reconhecido como refugiado o indivíduo que por motivo de perseguição ou de grave violação dos direitos humanos é obrigado a deixar seu país, para resguardar sua vida ou sua liberdade, segundo a Lei No 9.474, de 22 de julho de 1997. Embora recebam status legal diferenciado, os imigrantes haitianos encontram óbices similares a de refugiados. (SOARES; TIRLONI, 2019, p. 85).

Com o enorme contingente de novos migrantes chegando ao Brasil, tornam-se necessárias iniciativas de acolhimento e inclusão desta nova parcela da população não só ao mercado de trabalho, mas também à sociedade brasileira.

\section{O PLAC no Brasil}

O Ensino de Português para estrangeiros no Brasil toma diferentes formas dependendo da origem dos aprendizes e do próprio contexto de ensino. Dentre eles, é possível citar o Português como Língua Adicional (PLA), para falantes de outras línguas que se interessem por aprender o português por motivos diversos - trabalho, estudo, relacionamento -, Português como Língua Estrangeira (PLE), para falantes de outras línguas que vivam no Brasil e precisem, ou se interessem por, aprender a língua local e, por fim, há o Português como Língua de Acolhimento (PLAC). Diferentemente das outras modalidades de Ensino, o PLAc precisa trazer em seu conteúdo e suas formas de abordagem toda uma nova dimensão de práticas de ensino, uma vez que se trata do acolhimento de refugiados e migrantes forçados que chegam ao país sem uma política e estrutura eficiente de recepção (MIRANDA; LOPEZ, 2019).

No Brasil, encontramo-nos em um estágio do desenvolvimento das políticas linguísticas em que, em grande parte, voluntários e organizações não-governamentais acabam assumindo a tarefa do acolhimento de imigrantes estrangeiros. Este cenário é composto por uma série de desafios que vão desde os mais básicos, como a falta de verbas para a composição de cursos e remuneração de equipe, até os mais complexos, como o embate entre uma série de políticas públicas conflitantes que dificultam o processo de acolhimento e (re)integração dos imigrantes à sociedade civil (MIRANDA; LÓPEZ, 2019). Há, contudo, algumas instituições de ensino superior que desenvolvem cursos de PLAc, "[...] tais quais: a 
Universidade de Brasília, a Universidade de São Paulo, o Centro Federal de Educação Tecnológica de Minas Gerais e a Universidade Federal do Paraná" (LOPEZ; DINIZ, 2018, apud OLIVEIRA, 2019), além de iniciativas menores, porém não menos significantes para os contextos locais, como workshops e matérias de graduação e pós graduação em Linguística Aplicada, como na Universidade Federal de Minas Gerais, contexto onde foi produzido este artigo.

Independentemente de quem promove os cursos de PLAc, é preciso ter em mente que, diferentemente de outras modalidades de ensino de português, a sala de aula de PLAc é composta por diversas nacionalidades, idades variadas, heterogeneidade de perspectivas de sujeitos que, devido ao processo de migração forçada, de refúgio ou de migração humanitária, encontram-se esvaziados de agência pelo sistema de acolhimento do fluxo migratório do país de assentamento. Sem falar a língua local e, muitas vezes, sem redes de recepção de comunidades migrantes pré-estabelecidas no país, muitos dos migrantes que chegam ao Brasil se deparam com uma situação que não parece se encaixar na semântica da palavra acolhimento.

Em Multiletramentos e o Second Space no Ensino-Aprendizagem de PLAC: Da Teoria à Prática (2019), Ruano e Cursino apresentam uma nova abordagem do ensino de PLAc que a distingue fortemente do ensino de português como língua estrangeira do ensino de português como língua adicional. As autoras fazem uso do conceito de Grosso (2010) ao sugerirem que o aspecto do acolhimento faz referência direta ao "ensino de língua a um público adulto, em contexto migratório, orientada para a ação e interação real". Isto significa dizer que "a construção de significados de mundo para este público se faz de maneira muito distinta da realidade Brasileira". (RUANO; CURSINO, 2019).

Ao sugerir a língua de acolhimento como o ensino de idiomas para um público recémimerso em uma realidade linguístico-cultural nunca antes vivenciada no contexto de ensino de Curitiba, as autoras parecem estar em consonância com Papadopoulus (2019) em sua experiência no Campo de refugiado na Grécia, bem como diversas outras iniciativas de ensino de língua para estrangeiros em situação de migração forçada que têm dificuldade não só para se comunicar de forma prática, mas para compreender gêneros comuns na língua de acolhimento, ou para expressar suas inseguranças e construir novos laços com o novo lugar.

Dessa forma, a partir da associação de exemplos contemporâneos de contextos de migração forçada com a perspectiva dos não-lugares como cenários inerentes à pósmodernidade é possível afirmar que a integração dos estrangeiros à sociedade no país de acolhimento está intimamente ligada à sua capacidade de se relacionar com os novos espaços experienciados no país de acolhimento, de construir novas histórias, e de ressignificar suas identidades nestes novos contextos.

Tendo em mente a língua como parte fundamental da composição dos lugares, tornase ainda mais importante que os espaços de aprendizagem de português por migrantes forçados absorvam o caráter acolhedor do PLAc de maneira que o ensino não seja uma simples adaptação de métodos pré-concebidos (MIRANDA; LÓPEZ, 2019), mas que desenvolva novas 
formas de tornar o ensino-aprendizado acolhedor e de tornar a acolhida uma experiência de ensino-aprendizado.

\section{Transformando os não-lugares em lugares a partir do PLAc}

Como forma de construir um novo espaço não tradicional de ensino que leve em consideração a perspectiva do acolhimento, Ruano e Cursino (2019) baseiam-se em Campano (2007) ao propor o reconhecimento das experiências prévias dos próprios alunos como fonte de conhecimento para o desenvolver do letramento na língua de acolhimento.

Além disso, as autoras apropriam-se do conceito de Second Space ou Second Classroom para designar um ambiente tanto espacial quanto ideológico que vá além do confinamento das salas de aula e envolva as comunidades dos migrantes de forma a promover a inclusão da casa e da comunidade dos migrantes no processo de aprendizagem da língua de acolhimento. Assim, afirmam, "novos diálogos e relações são construídos, pois há uma dimensão afetiva acima de tudo" (RUANO \& CURSINO, 2019 2019, p.48). Em outras palavras, a partir de nossa leitura pós-moderna, a construção de um segundo espaço, que abarque também a comunidade tem implicações na facilitação do fortalecimento de laços, da valorização da cultura de origem dos migrantes e de suas perspectivas de mundo que quebram a lógica opressora da relação entre migrantes forçados e os não-lugares aos quais eles agora encontram-se circunscritos no país de acolhimento. O Second Space parece servir como uma espécie de catalizador para o processo de ressignificação dos espaços como lugares a partir da valorização do conteúdo e das experiências passadas dos sujeitos.

Ao propor, por exemplo, que os alunos de PLAc escrevam narrativas de sobrevivência, conforme anteriormente proposto por Campano (2007), a iniciativa incentiva os sujeitos a tornarem-se agentes, expressando no papel suas narrativas de tal forma que as elaboram como histórias que conectam seus passados e presentes no contínuo da trajetória de migração. Dessa maneira, com as palavras no papel, ou mesmo, por meio de expressão oral, os sujeitos-agentes (res)significam sua posição em relação ao novo mundo que os circunda, tecendo, portanto, novas formas de relacionar-se com os espaços. Essa relação, por sua vez, contribui para a (res)significação de suas próprias identidades no processo de transformação de meros espaços em novos lugares. Em consonância, Oliveira, em seu projeto de ensino de PLAc a Haitianos no contexto da preparação para o ENEM, explica que "Ao dar a oportunidade para que eles [os alunos] expressem sua identidade e compartilhem aspectos culturais que Ihe são próprios e caros, o professor pode contribuir para amenizar sentimentos negativos associados à migração forçada." (OLIVEIRA, 2019, p.69)

Outro projeto abordado por Ruano e Cursino (2019), o Literatura de Refúgio: vozes da migração, exílio, refúgio e diáspora, da UFPR, pode ser tido como um exemplo claro de estratégias de catalisação do processo de transformação de não-lugares em lugares por parte dos imigrantes. Ao "suscitar o diálogo entre estudantes, professores e pesquisadores, diversos órgãos públicos e privados e migrantes/refugiados acerca do que significa ser estrangeiro numa outra cultura e que condições este status impõe a toda a sociedade" (RUANO; CURSINO, 
2019, p.58) por meio de narrativas de migração originárias de outras culturas, e ao "levar a experiência para além dos muros da universidade com o intuito de possibilitar que as reflexões levantadas cheguem ao maior número de pessoas possível" (RUANO; CURSINO, 2019, p. 58), a coordenação do projeto subverte a ordem de (res)significação dos espaços de migração, que passam a não ser conduzidos somente por parte dos migrantes, mas também por parte daqueles que já fazem parte dos lugares, os moradores locais. Dessa forma, o projeto promove não somente a ressignificação dos lugares pelos migrantes, mas também a ressignificação dos migrantes pelo lugar e aqueles que o compõem.

\section{Conclusão}

O cenário de crescentes fluxos migratórios do mundo contemporâneo faz surgir a necessidade de se elaborar projetos criativos de reinserção de migrantes forçados e refugiados em seus novos contextos de assentamento. Longe de ser apenas mais uma modalidade de ensino de português como segunda língua, o ensino de Português como Língua de Acolhimento (PLAc) é criado e se aplica na confluência de diversas áreas epistemológicas, como a antropologia, a psicologia, e a linguística aplicada. Portanto, faz-se necessário o desenvolvimento de reflexões que auxiliem na contextualização dessa modalidade de ensino como um diálogo entre áreas de conhecimento.

Partindo de uma reflexão teórico-conceitual do campo epistemológico da antropologia, chegamos ao exemplo prático da experiência da estadia prolongada no abrigo por parte dos migrantes no estado do ACRE. Assim, foi possível apontar os efeitos nocivos da estadia prolongada no não-lugar sentidos pelos migrantes. Em sequência, uma revisão bibliográfica de artigos publicados sobre língua de acolhimento no Brasil e no mundo nos permitiu notar que os obstáculos enfrentados por diversas áreas epistemológicas no ensino de língua de acolhimento no Brasil fazem parte de uma tendência mundial que parece se repetir em diversas partes do planeta.

Dessa forma, o presente artigo buscou apresentar uma abordagem interdisciplinar dos estudos sobre PLAc ao propor a modalidade como uma ponte de ligação por meio da qual os não-lugares são transformados em lugares para aqueles que o vivenciam - os imigrantes. Essa abordagem permite reforçar a argumentação do ensino de PLAc como uma modalidade de acolhimento que precisa de estratégias que vão além das práticas tradicionais em salas de aula de ensino de segunda língua, para efetivamente atuarem no processo de transformação do local de assentamento em um lar para refugiados e migrantes forçados.

\section{Referências}

Alto Comissariado das Nações Unidas para Refugiados. Brasil torna-se o país com maior número de refugiados na América Latina. Disponível em: https://www.acnur.org/portugues/2020/01/31/brasil-torna-se-o-pais-com-maior-numerode-refugiados-venezuelanos-reconhecidos-na-america-latina/. Acesso em: 27 jul. 2020. 
ANDRADE, Luiza Silva de. Stuck in a Non-place: Haitian migrants' temporary settlement in Brazil and perceptions of time. 2013. 66 f. Dissertação (Mestrado em Social and Cultural Anthropology) - Sociale Wettenschappen Afdeling, Vrije Universiteit Amsterdam, Amsterdã, 2013.

AUGÉ, Marc. Não-Lugares: Introdução a uma antropologia da Supermodernidade. (1992) Tradução: Maria Lúcia Pereira. Campinas: Editora Papirus, 2018.

BAUMAN, Zygmunt. Modernidade líquida. Rio de Janeiro: Jorge Zahar Ed, 2001.

CAMPANO, Gerald. Immigrant Students and Literacy: Reading, Writing and Remembering. Nova York: Teachers College Press, 2007.

Instituto de Políticas Públicas en Derechos Humanos del Mercosur. Diagnóstico regional sobre migração haitiana instituto de políticas públicas en derechos humanos del mercosur. Disponível em: https://www.ippdh.mercosur.int/pt-br/publicaciones/diagnostico-regionalsobre-migracao-haitiana/. Acesso em: 29 jul. 2020.

MIRANDA, Yara Carolina Campos de; LÓPEZ, Ana Paula de Araújo. Considerações sobre a formação de professores no contexto de ensino de português como língua de acolhimento. In: Ferreira et al. (org.). Língua de Acolhimento: experiências no Brasil e no mundo. Belo Horizonte: Mosaico, 2019. p. 17-40.

OLIVEIRA, Desirée de Almeida. A preparação de imigrantes haitianos para a produção da redação do ENEM. 2019. 293 f. Dissertação (Doutorado em Estudos Linguísticos) - Programa de Pós-Graduação em Estudos Linguísticos, Universidade Federal de Minas Gerais. Belo Horizonte, 2019.

OLIVEIRA, Desirée de Almeida. A preparação de imigrantes haitianos para a produção da redação do ENEM. In: Ferreira et al. (org.). Língua de Acolhimento: experiências no Brasil e no mundo. Belo Horizonte: Mosaico, 2019. p. 63-82.

PAPADOPOULOU, Maria; TSIOLI, Sofia; ANDROULAKIS, George. A cocriação de espaços seguros e coloridos através do aprendizado informal para crianças refugiadas. In: Ferreira et al. (org.). Língua de Acolhimento: experiências no Brasil e no mundo. Belo Horizonte: Mosaico, 2019. p. 207-230.

RUANO, Bruna Pupatto; CURSINO, Carla. Multiletramentos e o Second Space no Ensinoaprendizagem de PLAc: da teoria à prática. In: Ferreira et al. (org.). Língua de Acolhimento: experiências no Brasil e no mundo. Belo Horizonte: Mosaico, 2019. p. 41-62.

SOARES, Laura; TIRLONI, Larissa Paula. Literatura em projeto de ensino de Português como língua de acolhimento para imigrantes haitianos. In: Ferreira et al. (org.). Língua de Acolhimento: experiências no Brasil e no mundo. Belo Horizonte: Mosaico, 2019. p. 83-102.

STAUDT, Taíse. Sou Diáspora: identidade e mobilidade nas memórias de haitianos no Brasil. 2018. 141 f. Monografia (Graduação em História). Universidade Federal da Fronteira Sul. Chapecó, 2018. https://doi.org/10.23899/relacult.v5i5.1475

Recebido em: 30/07/2020. Aceito em: 22/10/2020. 